\title{
Foundation for Virtual Experiments to Evaluate Thermal Conductivity of Semi- and Super-Conducting Materials
}

\author{
R. M. Bhatt
}

\author{
Department of Computer Science \\ HNB Garhwal University, Srinagar Garhwal 246174 India \\ rmbhatt77@yahoo.com
}

\section{R. P. Gairola}

\author{
Department of Physics, Birla Campus \\ HNB Garhwal University, Srinagar Garhwal 246174
}

\begin{abstract}
Thermal conductivity of solids provides an ideal system for analysis by conducting numerical experiment, currently known as virtual experiment. Here, the model is a numerical model, which is dynamic in nature, as the parameters are interrelated. The present paper discusses the steps involved to conduct virtual experiments using Automated Reasoning for simulation to evaluate the thermal conductivity of $\mathrm{Ge}, \mathrm{Mg}_{2} \mathrm{Sn}$ semiconducting and YBCO superconducting materials, close to the experimental values.
\end{abstract}

\section{Introduction}

Computers can help human to be creative[1] in a number of ways e.g. providing a continuous interaction between the man and machine, requires an even deeper understanding of the subject concerned. AI techniques are required to put the efforts near to the actual experiment in most economical manner. However, its considerable applications have not been applied in the thermal science [12]. To execute the Virtual Experiment (VE), considering various parameters, a model has been designed. Using Automated Reasoning(AR) for simulation, we find the fitness proven to be a reasonable facsimile of real experimental values for the thermal conductivity of Germanium (Ge), Magnesium stannide $\left(\mathrm{Mg}_{2} \mathrm{Sn}\right)$ semi-conducting and Yttrium Barium Cupric Oxide (YBCO) superconducting materials. 


\section{Foundation for Virtual Experiment}

Belonging to different fields viz. Economics, Physics, Biology etc., simulated approach has been applied e.g. usefulness of simulation, using models of economic systems [13], is reported as "Simulation can be used to experiment with new situations about which little or no information is available, so as to prepare for what may happen". Which is also described [19] as the process of designing a computerized model to conduct experiments. This examines the nature of human intelligence by doing soft computing that mimic the intelligence behaviour [6]. In AR, programs are written to prove mathematical theorems and it has been used as a reasoning engine to discover the knowledge. Here, the propositional logic and an alternative representation for proposition clauses have been used.

\section{1 - Applications of simulation}

Reasons can be given in favour of the VE as [17] "Such refinements provide a better understanding of physical problems which can not be obtained from experiment". AI techniques are used in physical science e.g. phase transformation [14]; for predictions [16]; to identify the distillation process [18]; and to design the complex thermal system [15].

Due to their inherent peculiar properties, semiconducting and superconducting systems promise wide applications. The various models, needed to solve a complex problem are mentioned in Fig. 2.1.

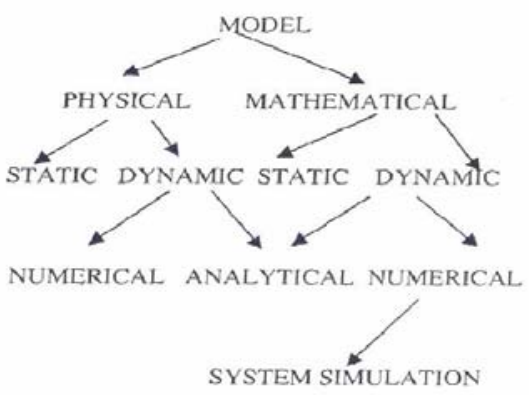

Fig.-1 : Types of Models

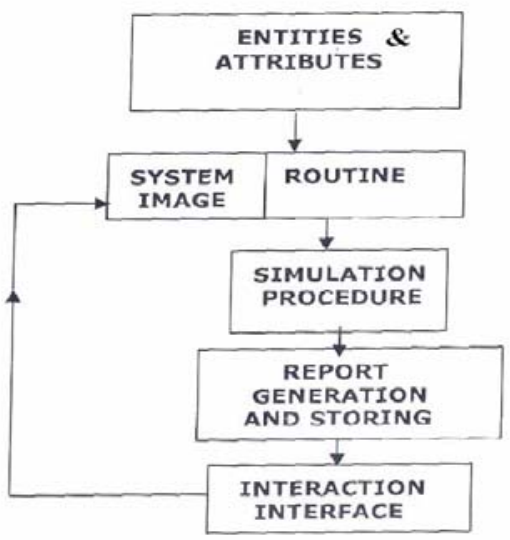

Fig.-2 :Flow Chart for Controlled Simulation 


\subsubsection{Stages for Simulation Task}

There are mainly five stages mapped-out for preparing for simulation as shown in the Fig. 2.1.1. An additional stage of interaction interface is being considered in the earlier 4 stages for simulation task[11]. This modification helps in controlling the simulation process. The first stage lists all parameters and activities. The second stage is to design the model by fitting the parameters and activities into the system image and routines separately to act like a model collectively. Thirdly, simulation algorithm is defined depending upon behaviour of the parameters. In the fourth stage, simulated responses are generated. In the fifth stage, interaction parameters are defined to provide a kind of feed back and help to retain the state of simulation and doing the repetitive process as required.

\subsubsection{Automated Reasoning}

Arithmetic and logical conditions have been applied and manipulated to decide whether the simulated results be accepted or neglected. The general format of the alternative representation for the propositional clause applied is:

$$
\text { IF }<>\text { THEN }<>\text { ELSE }<>
$$

During the simulation process, these conditions are applied and tested to get the best possible theoretical observations for fitting with the experimental values. The set of conditions as defined above are tested by using the logical AND operator. To gather the knowledge and to infer the simulated response for the fitness, rulebased systems has been applied as shown in the Fig. 2.1.2 of the logic tree.

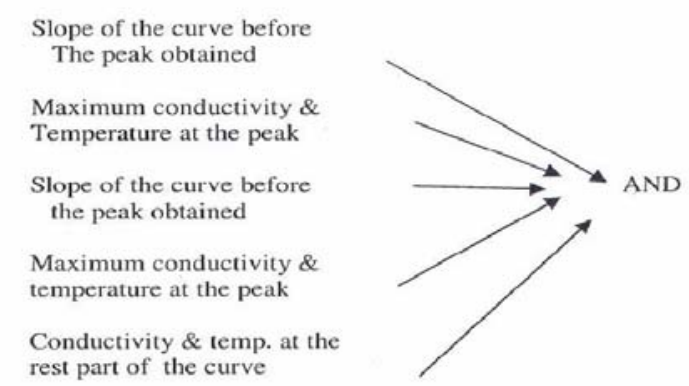

Fig. 2.1.2 : Logic Tree

\section{2 - Applications of two Dimensional Arrays}

By providing the feed back, interactively, appropriate values of different parameters are processed for the fitness of the hypothesis as shown in the Fig. 2.2, the 
self-explanatory diagram describing the interfacing algorithm. The preliminary development of this approach has been partially reported elsewhere[3].

The values for the conductivity $(\mathrm{K})$ have been generated in the form of a 2-D matrix/arrays as RESS(I,J), for a set of parameters, while the value of one of them has been altered. For a set of constant values of parameters - A, $\gamma, \alpha, \beta$ and, $\in$ and altered parameter $\delta$, a 2-D array of temperature v/s $\delta$ is shown in Table 2.2.

Table 2.2 : Storage of responses

\begin{tabular}{|l|l|l|l|l|}
\hline Temp/ $\delta$ & 200 & 210 & 220 & 230 \\
\hline 50 & 4.92 & 4.77 & 4.64 & 4.51 \\
\hline 100 & 4.30 & 4.15 & 4.00 & 3.86 \\
\hline 120 & 3.94 & 3.79 & 3.65 & 3.52 \\
\hline 160 & 3.29 & 3.15 & 3.02 & 2.91 \\
\hline
\end{tabular}

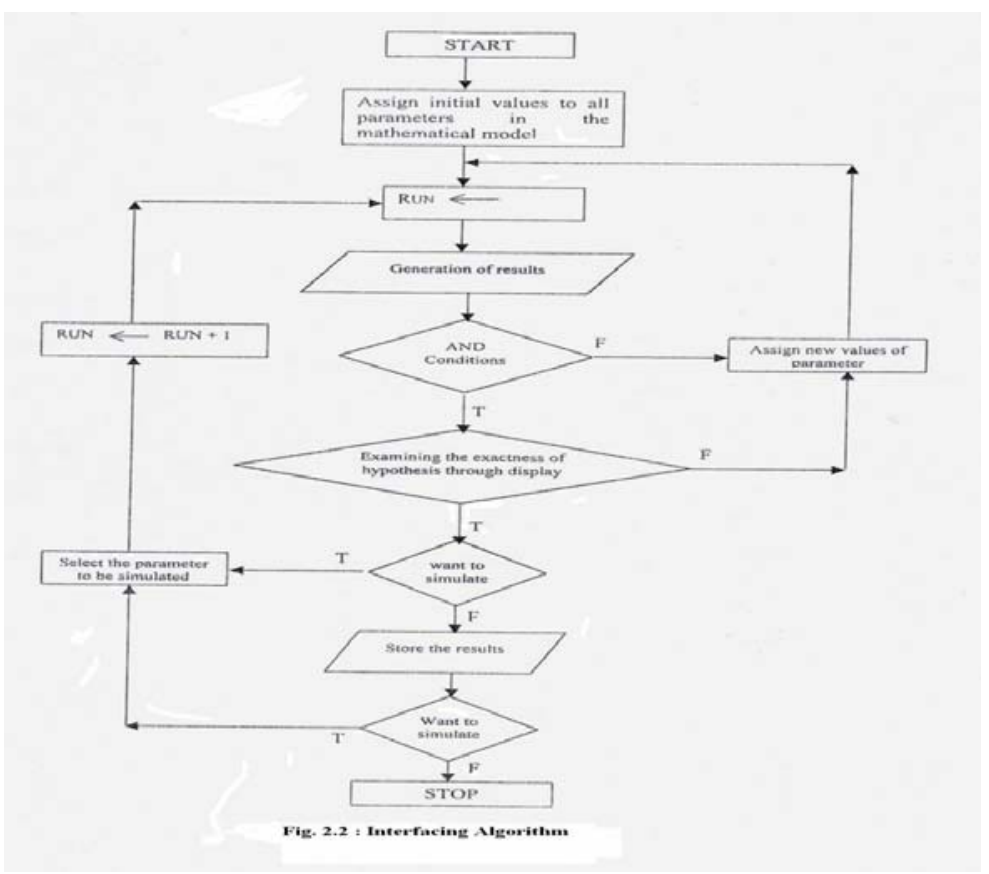

\section{Mathematical Model and Virtual Experiment}

The problem of integral calculations occurs very often in thermal science, where many parameters are involved to understand the nature of various scattering proc- 
esses, operating at different temperatures simultaneously. To evaluate the thermal conductivity, theoretical model (numerical) of Callaway[7] has been considered.

\subsection{Rule for Numerical Integration}

The functions in the theoretical physics besides being continuous are usually one or more times differentiable. Therefore, to increase the accuracy of the numerical integration for an equal number of mesh points, the Simpson rule[8] is applied. The mesh width of each interval between a and $b$, can be defined as, $h=(b-a) / n$, $\mathrm{n}$ (even) is the sub-subintervals where $\mathrm{a}=.00001, \mathrm{~b}=20.0$ and $\mathrm{n}=100$ have been taken into account. The error is only of the order of $h^{4}$, so precision is under controlled.

\subsection{Algorithm For Virtual Experimentation}

Logic is developed to execute the desired work and a computer program is developed accordingly as shown in the Interfacing Algorithm diagram. To compute speedily and to overcome the repetitive programming steps, subroutines are preferred. DO statement is extensively applied for various reasons, especially for arrays and subroutine handling. The computer program is developed in the FORTRAN-77 language[9].

\section{Test for different cases to evaluate thermal conductivity}

We have executed the above discussed logic on the proposed model, for instance, for the Ge, a semi-conducting material. After successfully testing its conductivity results in the temperature range from $2^{\circ} \mathrm{K}$ to $10^{\circ} \mathrm{K}$, we have proceeded further for detailed computations for the conductivity analyses for $\mathrm{Ge} \& \mathrm{Mg}_{2} \mathrm{Sn}$ semiconducting and YBCO superconducting samples.

\subsection{Test for Germanium(Ge) Semiconductor}

In analyzing the phonon conductivity of germanium, following equation for the thermal induced phonon relaxation rate is required,

$$
\tau^{-1}=v / F L+A \omega^{4}+\left(B_{1}+B_{2}\right) \omega^{2} T^{3}+D \omega^{3} T
$$


Here $\mathrm{v}$ is the sound velocity, $\mathrm{T}$ is the temperature and other symbols are the various parameters needed to test a particular theory. Values of different parameters used in the calculation for a preliminary test are taken from the earlier work[10], wherein the use of a computer program for achieving fitness in the wide range of temperature has been insisted. The set of values are :

$$
\begin{aligned}
& \mathrm{v}=3.5 \times 10^{5} \mathrm{~cm} / \mathrm{s} ; \mathrm{L}=.24 \mathrm{~cm} \cdot \mathrm{F}=.8 ; \theta_{\mathrm{D}}=376 ; \mathrm{A}=2.4 \times 10^{-44} \mathrm{~s}^{5} \\
& \mathrm{~B}_{1}+\mathrm{B}_{2}=2.77 \times 10^{-33} \mathrm{sec} \mathrm{K}^{-3} ; \mathrm{D}=1.203 \times 10^{-33} \mathrm{~s}^{2} \mathrm{~K}^{-1} .
\end{aligned}
$$

Test shows accuracy with the experimental results for the temperature $2{ }^{\circ} \mathrm{K}, 4{ }^{\circ} \mathrm{K}$, $6{ }^{\circ} \mathrm{K}$, and $10{ }^{\circ} \mathrm{K}$, which are $.474, .261, .504, .791$ and $.985 \mathrm{~W} / \mathrm{cm}^{-1} \mathrm{~K}^{-1}$, respectively. Due to fitness of test, it is further carried up to the temperature of $40^{\circ} \mathrm{K}$. The Table 4.1.1 illustrates the different values of the parameters and their simulated inferences for the conductivity values are shown in the Table 4.1.2.

\begin{tabular}{|c|c|c|c|c|}
\hline \multirow{2}{*}{ Parameters } & \multicolumn{4}{|c|}{ Values $\longrightarrow$} \\
\hline & I & II & III & IV \\
\hline $\mathrm{v}\left(\mathrm{x} 10^{5} \mathrm{~cm} / \mathrm{sec}.\right)$ & 3.5 & 3.5 & 3.5 & 3.5 \\
\hline $\mathbf{L}$ & .24 & .24 & .24 & .243 \\
\hline $\mathbf{F}$ & .80 & .77 & .77 & .77 \\
\hline$\theta_{\mathbf{D}}$ & 376 & 376 & 376 & 376 \\
\hline $\mathrm{A}\left(\mathrm{x} 10^{-44}\right.$ sec. $\left.^{3}\right)$ & 2.4 & 2.4 & 2.4 & 2.4 \\
\hline $\mathrm{B}_{1}+\mathrm{B}_{2}\left(\mathrm{x} 10^{-23} \mathrm{sec} . \mathrm{K}^{-3}\right)$ & 2.77 & 3.43 & 3.43 & 3.43 \\
\hline $\mathrm{D}\left(\mathrm{x} 10^{-33} \mathrm{sec}^{3} \mathrm{~K}^{-1}\right)$ & 1.203 & 1.433 & 3.423 & 3.334 \\
\hline Max. Conductivity $\left(\mathbf{x 1 0}^{7}\right)$ & 21.50 & 18.61 & 12.62 & $\mathbf{1 2 . 8 3}$ \\
\hline (at Temp. ${ }^{0} \mathrm{~K}$ ) & 17 & 16 & 18 & 18 \\
\hline
\end{tabular}

Table 4.1.1: Parameters and Values for Ge

\begin{tabular}{|c|c|c|c|c|c|c|c|c|c|c|c|}
\hline $\begin{array}{l}\text { Re- } \\
\text { sponse }\end{array}$ & $\begin{array}{c}\mathbf{K} \\
\left.f^{\left(x 10^{7}\right.}\right)\end{array}$ & $\begin{array}{c}\text { Temp } \\
\stackrel{2}{\longrightarrow}\end{array}$ & 4 & 8 & 10 & 15 & 20 & 25 & 30 & 35 & 40 \\
\hline I & Cond. & .49 & 3.17 & 1.20 & 1.58 & 2.10 & 2.10 & 1.26 & 1.58 & 1.32 & 1.10 \\
\hline II & Cond. & .47 & 2.98 & 1.09 & 1.42 & 1.80 & 1.80 & 1.52 & 1.32 & 1.05 & 0.91 \\
\hline III & Cond. & .45 & 2.52 & 7.79 & 0.97 & 1.20 & 1.24 & 1.09 & 0.97 & 0.80 & 0.70 \\
\hline IV & Cond. & .46 & 2.56 & 7.93 & 0.99 & 1.22 & 1.26 & 1.11 & 0.98 & 0.81 & 0.71 \\
\hline
\end{tabular}

Table 4.1.2: Thermal Conductivity measures for Ge

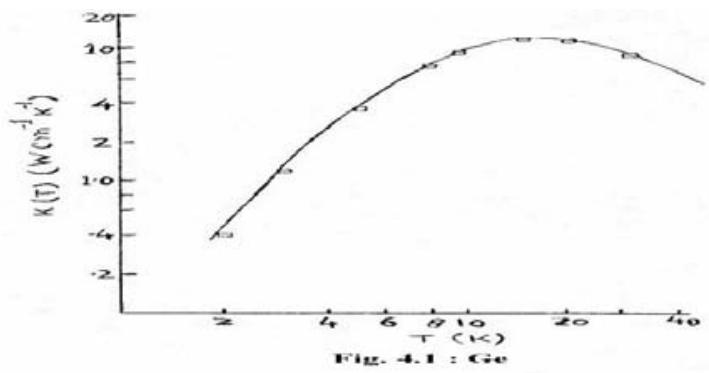


These four inferences for thermal conductivity measurements are closely examined and the values shown against the $\mathrm{IV}^{\text {th }}$ observations (marked with $*$ ) are found fit, graphically depicted in the Fig. 4.1, where circle shows the experimental point and the present analysis has been shown as the curve-line.

\subsection{Test for Magnesium Stannide ( $\left.\mathrm{Mg}_{2} \mathrm{Sn}\right)$ Semiconductor}

We consider the following expression for relaxation time,

$\tau^{-1}(\omega)=(v / F L)+A \omega^{4}+\left[B_{1}+B_{2} \exp .(-\Theta / a T)\right] \omega^{2} T^{3}+D \omega^{3} T$

It has been a usual practice, to generally neglect the exponential temperature dependence of the parameter $\mathrm{B}_{2}$ for the conductivity calculation, representing Umklapp phonon-scattering and both $\mathrm{B}_{1}$ (normal phonon scattering parameter) and $\mathrm{B}_{2}$ are lumped into a single parameter $\mathrm{B}$, assumed to be independent of $\mathrm{T}$. Therefore, $\mathrm{B}_{2}$ is taken to depend upon $\mathrm{T}$, exponentially, in the analysis. Table 4.2.2 shows four simulated response against the values of different parameters as shown in the Table 4.2.1.

Table 4.2.1: Parameters and Values for $\mathrm{Mg}_{2} \mathrm{Sn}$

\begin{tabular}{|c|c|c|c|c|}
\hline \multirow{2}{*}{$\downarrow$ Parameters } & \multicolumn{4}{|c|}{ Values $\rightarrow$} \\
\hline & I & II & III & IV \\
\hline $\mathrm{v}\left(\mathrm{x} 10^{5} \mathrm{~cm} / \mathrm{sec}.\right)$ & 359 & 359 & 359 & 359 \\
\hline $\mathbf{L}$ & .11 & .11 & .10 & .10 \\
\hline $\mathbf{F}$ & .54 & .54 & .54 & .54 \\
\hline$\propto$ & 2.0 & 2.5 & 2.5 & 2.5 \\
\hline$\theta_{\mathbf{D}}$ & 154 & 154 & 154 & 154 \\
\hline A $\left(\mathbf{x ~ 1 0}{ }^{-44}\right.$ sec. $\left.^{3}\right)$ & 6.3 & 6.3 & 6.3 & 6.3 \\
\hline $\mathbf{B}_{1}\left(\mathbf{x 1 0}^{-23} \mathrm{sec}^{\left.-\mathrm{K}^{-3}\right)}\right.$ & 7.0 & 7.0 & 7.7 & 7.7 \\
\hline $\mathbf{B}_{2} \times 10^{-23}$ sec.K $\left.{ }^{-3}\right)$ & 4.7 & 4.7 & 4.7 & 4.7 \\
\hline $\mathrm{D}\left(\mathrm{x} \mathbf{1 0}^{-33} \mathrm{sec}^{3}{ }^{3} \mathrm{~K}^{-1}\right)$ & 2.75 & 2.75 & 2.75 & 2.95 \\
\hline Max. Conductivity $\left(\mathbf{x 1 0}^{7}\right)$ & 6.483 & 6.398 & 6.088 & 5.909 \\
\hline (at Temp. ${ }^{0} \mathbf{K}$ ) & 16 & 14 & 14 & 14 \\
\hline
\end{tabular}

Table 4.2.2: Thermal Conductivity measures for $\mathrm{Mg}_{2} \mathrm{Sn}$

\begin{tabular}{|c|c|c|c|c|c|c|c|c|c|c|c|}
\hline $\begin{array}{l}\text { Re- } \\
\text { sponse }\end{array}$ & $\left.\right|_{\left(\times 10^{7}\right)} ^{K}$ & $\begin{array}{c}\text { Temp } \\
2 \\
\end{array}$ & 6 & 8 & 10 & 14 & 20 & 26 & 30 & 36 & 40 \\
\hline I & Cond. & .96 & 2.37 & 3.89 & 5.16 & 6.45 & 5.74 & 4.08 & 3.15 & 2.15 & 1.69 \\
\hline II & Cond. & .96 & 2.37 & 3.89 & 5.16 & 6.39 & 5.47 & 3.71 & 2.79 & 1.87 & 1.46 \\
\hline III & Cond. & .89 & 2.21 & 3.65 & 4.87 & 6.08 & 5.25 & 3.57 & 2.70 & 1.81 & 1.42 \\
\hline IV & Cond. & .68 & 2.17 & 3.57 & 4.74 & 5.90 & 5.10 & 3.49 & 2.64 & 1.78 & 1.40 \\
\hline
\end{tabular}


The corresponding results for thermal conductivity are examined and the values of the II observations(marked with *) are found fit, shown by the curve-line in Fig. 4.2 where the experimental data is shown as circle-points.

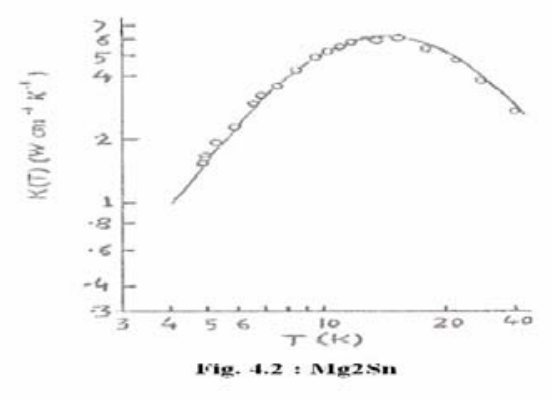

\subsection{Test for Yttrium Barium Cupric Oxide (YBCO) superconductors}

In computing the thermal conductivity of YBCO superconductors, behaviour has also been examined by earlier workers [2]. We have considered the Callaway's model, which is also used by Tewordt et al.[20] in a modified form-

$K=A t^{3} \int x 4 e^{x} /\left[\left(e^{x}-1\right)^{2} \cdot F(t, x)\right] d x$

$F(t, x)=\left[1+\alpha x^{4} t^{4}+\beta x^{2} t^{2}+\gamma t x g(x, y)+\delta x^{3} t^{4}+\left(\in x^{2} t^{5}\right]\right.$

$\mathrm{A}, \alpha, \beta, \gamma, \delta$ and $\in$ are scattering strengths due to boundary scattering, point defect scattering, sheet like fault, electron-phonon scattering, interference scattering and three phonon scattering. Corresponding maximum conductivity values are shown in the Table 4.3.1.

Table 4.3.1: Thermal Conductivity measures for YBCO

\begin{tabular}{|l|l|l|l|l|l|l|l|l|}
\hline Response & Max.Cond. & Temp & $\mathbf{A}$ & $\alpha$ & $\beta$ & $\gamma$ & $\delta$ & $\in$ \\
\hline I & $\mathbf{3 . 5 0}$ & $\mathbf{7 0}$ & $\mathbf{4}$ & $\mathbf{1 5}$ & $\mathbf{5 0}$ & $\mathbf{5 0}$ & $\mathbf{2 1 0}$ & $\mathbf{. 0 1}$ \\
\hline II & $\mathbf{3 . 8 2}$ & $\mathbf{6 0}$ & $\mathbf{4}$ & $\mathbf{2 5}$ & $\mathbf{5 0}$ & $\mathbf{5 0}$ & $\mathbf{2 1 0}$ & $\mathbf{. 0 1}$ \\
\hline III & $\mathbf{4 . 1 4}$ & $\mathbf{6 0}$ & $\mathbf{4}$ & $\mathbf{1 5}$ & $\mathbf{5 0}$ & $\mathbf{5 0}$ & $\mathbf{2 1 0}$ & $\mathbf{. 0 1}$ \\
\hline IV & $\mathbf{3 . 8 1}$ & $\mathbf{7 0}$ & $\mathbf{5}$ & $\mathbf{1 5}$ & $\mathbf{5 0}$ & $\mathbf{5 0}$ & $\mathbf{2 1 0}$ & .01 \\
\hline
\end{tabular}

Table 4.3.2: Thermal Conductivity measures for YBCO

\begin{tabular}{|c|c|c|c|c|c|c|c|c|c|c|}
\hline \multirow{2}{*}{$\begin{array}{l}\text { Re- } \\
\text { sponse }\end{array}$} & \multirow{2}{*}{$\int_{\left(x 10^{7}\right)}^{K}$} & \multicolumn{9}{|c|}{ Temp $\longrightarrow$} \\
\hline & & 10 & 20 & 30 & 40 & 80 & 100 & 120 & 140 & 160 \\
\hline I & Cond. & .68 & 1.67 & 2.35 & 2.73 & 3.03 & 2.95 & 2.82 & 2.68 & 2.54 \\
\hline II & Cond. & 1.39 & 2.73 & 3.40 & 3.70 & 3.70 & 3.49 & 3.24 & 2.99 & 2.75 \\
\hline III & Cond. & 1.43 & 2.87 & 3.63 & 3.98 & 4.03 & 3.80 & 3.54 & 3.27 & 3.02 \\
\hline IV & Cond. & .86 & 2.09 & 2.93 & 3.41 & 3.79 & 3.68 & 3.53 & 3.35 & $\overline{3.17}$ \\
\hline
\end{tabular}


We have found positive results in the temperature range from $10-160{ }^{\circ} \mathrm{K}$ and fitness (shown as curve-line) with the experimental results (shown as circle-point) from the IV observations of Table 4.3.2, as shown in the Fig. 4.3.

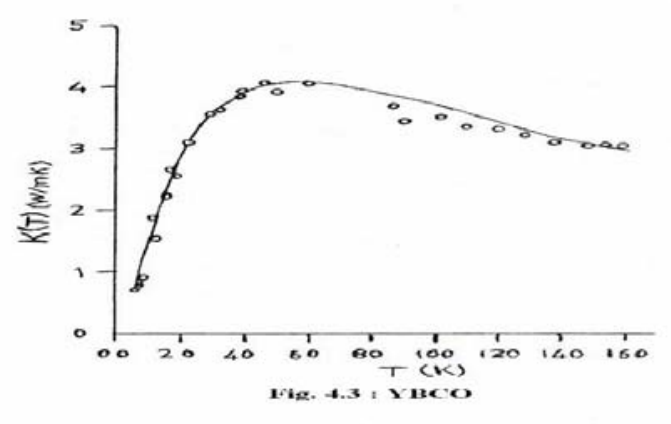

\section{Model Validation}

The model has also been validated in two cases. First case of the semiconducting material Ge, shows[5] a good agreement between theory and experiment in the temperature range 2 to $100^{\circ} \mathrm{K}$. For the second case, similar approach also enables to analyse the three different samples of YBCO superconductors[4] in the temperature range 0 to $260{ }^{\circ} \mathrm{K}$ and the interference scattering \& exponential temperature dependence lead to a good agreement with the experimental data.

\section{CONCLUSION}

It emerges that the VE has immense capabilities to yield good results, within the prescribed automated reasoning and the interface algorithm,. In performing VE over the different models for these materials ( $\mathrm{Ge}, \mathrm{Mg}$ and $\mathrm{YBCO}$ ), the various parameters have been considered so as to search for the unusual features or properties might provide a background for understanding the mechanisms.

\section{ACKNOWLEDGEMNT}

Dr. Bhatt wants to sincerely acknowledge the encouragement received from his respected and beloved father Sri Rameshwar Prasad Bhatt who passed away on $16^{\text {th }}$ of Feb., 2007. Computational facilities availed at Deptt. of Computer Science, HNB Garhwal University is also sincerely acknowledged. 


\section{References}

1. Adkins Gerald and Pooch Udo W (1987) Computer Simulation: A tutorial, in selected reports in Software. In: Marvin V. Zelkowitz(ed) The Computer Society of the IEEE, 384:381-393

2. Aubin H Behnia K Ribault M Taillfer L and Gagnon R (1997) Zeit. fur Physik B-103:149

3. Bhatt R M and Gairola R P (1997) Simulation for conductivity curve-fitting in YBCO superconductors, In: Venkata Rao and T.P.Rama Rao (ed) IT for Organisational Excellence, TMH, New Delhi

4. Bhatt R M Gairola R P (2001) Simulation Analysis for lattice thermal conductivity of YBCO superconductors. Current Science 80(7):864-867

5. Bhatt R M Gairola R P (2002) Simulation Analysis for phonon conductivity of Germanium. In: proc. of XXXVII Annual CSI, Harnessing and managing knowledge, CD produced by www.productreach.net, Bangalore

6. Bonnet A (1985) A I, Promise and Performance. Prentice Hall, N.J.

7. Callaway Joseph (1959) Phys. Rev. 113: 1046.

8. Chandra Suresh (1995) FORTRAN programming and numerical techniques. Sultan chand \& Sons, New Delhi

9. Digital Research Fortran Language reference manual (1983), first edition, release note 02-1985, California, USA

10. Gairola R P(1985) Phys. St. Sol. (b) 125: 65

11. Geoffrey Gordan (2007) System simulation, 2nd edn. Prentice-Hall of India, New Delhi

12. Krieth F Timmerhaus K Lior N Shaw H Shah R K Bell K J Diller K R Valvano J W (2000)Applications. In: Frank Kreith(ed) The CRC Hndbook of Thermal Engineering, Boca Raton: CRC Press LLC

13. Naylor T H (1971) Computer simulation experimentation with models of economic systems. John Wiley and sons, New York

14. Osetsky Yu N (1998) Computer-simulation study of high temperature phase stability in iron. Phys. Rev. B-57(2):755-763

15. Paoletti B Sciubba E (1997) Artificial Intelligence in thermal systems design: Concept and Applications. In: R. F. Boehm(ed) Developments in the design of thermal systems, Cambridge University Press, New York

16. Pavlovic A S Suresh Babu V and Mohindar Seehra S (1996) High-temperature thermal expansion of binary alloys of $\mathrm{Ni}$ with $\mathrm{Cr}$, Mo and Re: a comparison with molecular dynamics simulation. J. Phys. Cond. Matter 8:3139-3144

17. Rajaraman V (1997) Simulation with supercomputers, in proc. of Int'l conf. on cognitive systems, Vol. II, Allied, New Delhi

18. Rasmussen K H Nielsen C S Jorgensen S (1990) Identification of distillation process dynamics comparing process knowledge and black box based approaches. In: Proced. Am. Control Conf. 3116-3121

19. Shanon R F (19975) Simulation: A survey with research suggestions. AIIE Transaction. 7(3)

20. Tewardt L and Wolkhausan (1989)Th. St. Commun. 70: 839. 